\title{
Ornithine lipid of Mycobacterium tuberculosis: its distribution in some slow- and fast-growing mycobacteria
}

\author{
Marie-Antoinette Lanéelle, ${ }^{*}$ Danièle Promé, Gilbert Lanéelle and Jean-Claude Promé \\ Centre de Biochimie et Génétique Cellulaires du CNRS et Université P. Sabatier, 118 route de Narbonne, \\ 31062 Toulouse Cédex, France
}

(Received 19 October 1989; revised 5 December 1989; accepted 4 January 1990)

\begin{abstract}
An ornithine-amide lipid is present in Mycobacterium tuberculosis. Its structure was established by a combination of chemical analysis and mass spectrometry. 3-Hydroxyoctadecanoic and 3-hydroxyeicosanoic acids (and homologues) were found to be linked through an amide bond to the $\alpha$-amino group of L-ornithine, the hydroxyl group of the fatty acid being esterified mainly by tuberculostearic acid (10-methyloctadecanoic acid). This ornithine-amide lipid was detected in several other slow-growing pathogenic mycobacteria by thin layer chromatography, but not in an avirulent strain (H37 Ra) of $M$. tuberculosis. In each case mass spectrometry showed that all the structures were identical, thus revising an earlier reported structure for the lipid from $M$. bovis.
\end{abstract}

\section{Introduction}

Ornithine- or lysine-amide lipids are the most frequently detected amino acid lipids that are devoid of phosphorus. Their most common basic structure is an ornithine residue acylated on its $\alpha$-amino group by a long-chain hydroxy-fatty acid, this hydroxy group being itself acylated by a non-hydroxylated fatty acid (Fig. 1).

Isolation of these lipids by the usual chromatographic procedures is hampered by their polarity which is close to that of phospholipids, particularly phosphatidylethanolamine which is relatively abundant in many bacterial genera. Purification difficulties could explain several discrepancies in published work between the proposed structures, particularly concerning the presence (Promé et al., 1969; Thiele \& Schwinn, 1973) or the absence (Kawai \& Yano, 1983) of a diol residue esterifying the carboxyl group of ornithine. Moreover, diol lipids have been detected in some bacteria (Demarteau-Ginsburg \& Miquel, 1962; Batrakov \& Bergelson, 1978).

Ornithine- and lysine-amide lipids have some similarities with phosphatidylethanolamine, and Wilkinson (1972) postulated that they could replace this commonly found phospholipid in the membrane: when Pseudomonas fluorescens was grown in phosphate-limited medium, an ornithine-amide lipid was the major lipid component (Minnikin \& Abdolrahimzadeh, 1974).

Abbreviations: FAB, fast-atom bombardment; CID-MIKE spectrum, collision induced dissociation-mass analysed ion kinetic energy spectrum.

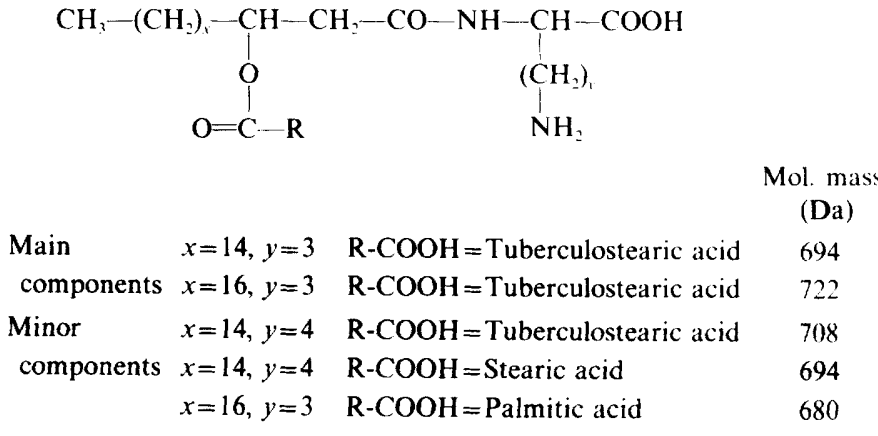

Fig. 1. Structure of the amino acid amide-lipid from $M$. tuberculosis strain Canetti. Ornithine, $y=3$; lysine, $y=4$.

Ornithine- and lysine-amide lipids have been found in many Gram-negative bacteria (for a review see Wilkinson, 1988) including several pathogens, e.g. Brucella (Promé et al., 1969; Thiele \& Schwinn, 1973), Bordetella (Thiele \& Schwinn, 1973), Flavobacterium (Asselineau et al., 1988; Kawai et al., 1988a) and Pseudomonas (Kawai et al., 1988b). They have not been detected in Grampositive bacteria (for a review see O'Leary \& Wilkinson, 1988), except in the order Actinomycetales, e.g. in Mycobacterium bovis (BCG) (Promé et al., 1969) and in some Streptomyces species (Batrakov \& Bergelson, 1978).

There is a growing interest in mycobacterial lipids. Some of them are toxic for host cells or are effectors for the immune system (Lederer, 1979; Mehra et al., 1984) and their biological activities can partly explain the 
pathogenic effects of mycobacteria. Biologically active mycobacterial lipids are mainly glycolipids, but ornithine- and lysine-amide lipids, have been shown to be haemagglutinins (Kawai \& Yano, 1983), and their $O$ deacylated derivatives are haemolytic (Kawai et al., $1988 \mathrm{~b}$ ). Moreover, they may play a role in bacterial development in the host by their ability to substitute for phosphatidylethanolamine.

We report here that ornithine-amide lipids are present in the tubercle bacilli ( $M$. tuberculosis-bovis complex) and in some other slow-growing mycobacteria. The structure of the compound isolated from $M$. tuberculosis (strain Canetti) was elucidated; this allowed us to revise the structure formerly proposed for the ornithine-amide lipid from $M$. bovis (BCG).

\section{Methods}

Mycobacterial strains and cultures. Strains used are listed in Table 1. They were kindly supplied by Dr H. David (Service des Mycobactéries et de la Tuberculose, Institut Pasteur, Paris, France). They were grown on Sauton medium at $37^{\circ} \mathrm{C}$, until a thick surface layer had been produced ( 3 to 5 weeks). Cells were harvested by decantation, then killed and extracted by addition of $\mathrm{CHCl}_{3} / \mathrm{CH}_{3} \mathrm{OH}(1: 2, \mathrm{v} / \mathrm{v})$.

Lipid extraction and purification. Cells were successively extracted twice with $\mathrm{CHCl}_{3} / \mathrm{CH}_{3} \mathrm{OH}(2: 1, \mathrm{v} / \mathrm{v})$. For preparative-scale purification, the crude lipid fraction was first separated on a Florisil column (Daffé et al., 1987). Ornithine-amide lipids were eluted together with phospholipids using solvent $\mathrm{A}\left[\mathrm{CHCl}_{3} / \mathrm{CH}_{3} \mathrm{OH} / \mathrm{H}_{2} \mathrm{O}(65: 25: 4\right.$, by vol.)]. Pure ornithine-amide lipid from $M$. tuberculosis (strain Canetti) was then obtained by chromatography on a DEAE-Trisacryl column (acetate form; $2 \mathrm{~cm}$ diam. $\times 5 \mathrm{~cm}$ long per $100 \mathrm{mg}$ crude lipid loaded). Crude lipid (at least $200 \mathrm{mg}$ ) dissolved in $\mathrm{CHCl}_{3}$ was loaded onto the column and eluted twice with $50 \mathrm{ml}$ portions of the following solvents in succession: $\mathrm{CHCl}_{3} ; \mathrm{CHCl}_{3} / \mathrm{CH}_{3} \mathrm{OH}(9: 1$, then $7: 3$ then $1: 1)$. All the ornithine lipid was eluted by $9: 1 \mathrm{CHCl}_{3} / \mathrm{CH}_{3} \mathrm{OH}$.

For rapid screening of the various mycobacteria for the presence of lysine- and ornithine-amide lipids, a sample of the total lipid extract was subjected to mild alkaline deacylation $\left[0.5 \% \mathrm{KOH}\right.$ in $\mathrm{CH}_{3} \mathrm{OH} /$ benzene $(2: 1, \mathrm{v} / \mathrm{v})$ for $1 \mathrm{~h}$ at $\left.37^{\circ} \mathrm{C}\right)$; the ether-soluble fraction obtained after acidification was spotted onto a thin-layer chromatography (TLC) plate. The $O$-deacylated ornithine- (or lysine-) amide lipid (formula 1 in Results and Discussion) gave a ninhydrin-positive spot on thin-layer chromatograms at $R_{F} 0 \cdot 09$ (solvent $\mathrm{A}$ ), while the intact compound had an $R_{F}$ of 0.44 (just below phosphatidylethanolamine; $R_{F}$ $0 \cdot 50$ ). Each time amide-linked lipids were detected in small amounts of crude lipid extracts by using the above rapid procedure, fast checking of the structure of the native amide-lipid was determined by mass spectrometry (MS) of material purified on laboratory-made analytical thin-layer plates (Kieselgel G, Merck; solvent A) which were suitable for small-scale preparative work (up to $10 \mathrm{mg}$ per plate). The amidelipid was scraped off and eluted from the zone just below phosphatidylethanolamine.

Amino acid analysis. Amide bonds were cleaved by acidic hydrolysis of the intact lipid $\left(6 \mathrm{M}-\mathrm{HCl}\right.$ overnight at $\left.110^{\circ} \mathrm{C}\right)$. Amino acids were identified either by paper chromatography using solvent B (butanol/ acetic acid/water; $4: 1: 1$, by vol.), or by gas-liquid chromatography (GC) of their di- $N$-trifluoroacetyl $R$-(-)-but-2-yl esters, which allowed the stereochemistry of the amino acids to be determined. These
Table 1. Presence of ornithine- or lysine-lipids in slow-and fast-growing mycobacteria

The presence $(+)$ or absence $(-)$ of the lipids was determined by TLC.

\begin{tabular}{|c|c|c|}
\hline \multirow[b]{2}{*}{ Strain } & \multicolumn{2}{|c|}{ Phosphorus-free lipoamino acids } \\
\hline & With amide bond & Without amide bond \\
\hline \multicolumn{3}{|l|}{ (a) Slow-growing } \\
\hline \multicolumn{3}{|l|}{ M. tuberculosis } \\
\hline Canetti 60 & + & - \\
\hline H37 Rv & + & - \\
\hline H37 Ra & - & - \\
\hline IP 88628* & + & - \\
\hline \multicolumn{3}{|l|}{ M. bovis } \\
\hline BCG Pasteur & + & - \\
\hline IP 140020005 & + & - \\
\hline IP 140020011 & + & - \\
\hline Vallée & + & - \\
\hline \multicolumn{3}{|l|}{ M. marinum } \\
\hline IP 140120001 & + & - \\
\hline IP 140120003 & + & - \\
\hline АТCC 927 & + & - \\
\hline \multicolumn{3}{|l|}{ (b) Fast-growing } \\
\hline \multicolumn{3}{|l|}{ M. smegmatis } \\
\hline ATCC 607 & - & - \\
\hline \multicolumn{3}{|l|}{ M. aurum } \\
\hline ATCC 23366 & - & + \\
\hline $\mathrm{A}+\boldsymbol{+}$ & - & - \\
\hline \multicolumn{3}{|l|}{ M. phlei } \\
\hline$(\text { IST })_{\ddagger}^{+}$ & - & + \\
\hline ATCC 19249 & - & - \\
\hline
\end{tabular}

* Recent (1988) clinical isolate.

$\dagger$ Also known as 'strain Rebuffet' in the Institut Pasteur (Paris, France) collection.

$\ddagger$ Institut de Sérothérapie de Toulouse (France).

derivatives were prepared as follows. The dried amino acids were treated with $0.1 \mathrm{ml}$ trifluoroacetic anhydride for $1 \mathrm{~h}$ at room temperature. Excess reagent was allowed to evaporate in a desiccator in the presence of pellets of $\mathrm{NaOH}$. Butyl esters were then prepared by adding $0 \cdot 1 \mathrm{ml} R$-( -)-2-butanol and $6 \mu \mathrm{l}$ acetyl chloride, followed by heating for $4 \mathrm{~h}$ at $80^{\circ} \mathrm{C}$. The two successive derivatizations were done in the same tightly sealed screw-cap bottle.

The position of the amide linkage in the ornithine-amide lipids was determined by $N$-dansylation. The lipid $(1 \mathrm{mg}$ ) was dissolved in $0.1 \mathrm{ml}$ $\mathrm{CHCl}_{3} / \mathrm{CH}_{3} \mathrm{OH}(1: 1, \mathrm{v} / \mathrm{v})$. Triethanolamine $(1 \mu \mathrm{l})$ was added, and a total of $1 \mathrm{mg}$ dansyl chloride dissolved in $0.1 \mathrm{ml} \mathrm{CH}_{3} \mathrm{OH}$ was added as two successive $50 \mu \mathrm{l}$ additions with $1 \mathrm{~h}$ allowed after each addition for the reaction to reach completion. After acid hydrolysis (see above) dansylornithine or dansyllysine were identified by TLC (solvent A). Commercial $\varepsilon$-dansyllysine (Sigma) and mixtures of synthetic monodansyl derivatives of each of the dibasic amino acids were used as references.

Mass spectrometry. The mass spectrometer was a HS-ZAB-2F (VG Analytical) associated with a VG 2035 Data System, using a PDP-8A computer. Fast-atom bombardment (FAB) spectra were generated by a neutral xenon atom beam of $8 \mathrm{keV}$. Glycerol was used as a matrix. The CID-MIKE (collision-induced dissociation-mass analysed ion kinetic energy) experiments were done using the multichannel recording 
system. Helium was introduced into the collision cell located on the second field force area in such a way that a signal arising from the pseudomolecular ion was reduced to approximately $30 \%$ of its original value. The scan speed was $800 \mathrm{eV} \mathrm{s}^{-1}$.

Gas-liquid chromatography coupled to mass spectrometry (GC/MS) used the same chromatographic conditions as for GC alone (see below) except that a DANI-3800 chromatograph was used. The mass spectrometer was fitted with an electron-impact ionization source (70 $\mathrm{eV})$. The interface temperature was $200^{\circ} \mathrm{C}$. The scan speed was $1 \mathrm{~s}$ per decade.

Miscellaneous techniques. GC was done on a Girdel-30 apparatus equipped with a fused silica capillary column $(0.32 \mathrm{~mm}$ inside diam. $\times 25 \mathrm{~m}$ long) coated with OV1. Helium was used as carrier. The oven temperature was programmed to rise at $2{ }^{\circ} \mathrm{C} \mathrm{min}^{-1}$ from 100 to $280^{\circ} \mathrm{C}$.

Infra-red spectra of solid film lipid samples were obtained on a Perkin-Elmer 1600 FITR.

Trimethylsilyl derivatives were prepared as described previously (Daffé et al., 1983).

\section{Results and Discussion}

The infra-red spectrum of the lipoamino acid isolated from $M$. tuberculosis exhibited absorption bands characteristic of an ornithine- or lysine-amide lipid (Kawai et al., $1988 b)$ : an $\mathrm{N}-\mathrm{H}$ stretching band $\left(3320 \mathrm{~cm}^{-1}\right)$, a C-O stretching band of an ester group $\left(1725 \mathrm{~cm}^{-1}\right)$, an ionized carboxyl group at $1580 \mathrm{~cm}^{-1}$ and amide I and II bands (1630 and $1530 \mathrm{~cm}^{-1}$ ). Infra-red spectroscopy allowed rapid identification of these compounds with about $1 \mathrm{mg}$ of the isolated lipid.

Amino acid analysis after acidic hydrolysis showed that L-ornithine was the main amino acid, with trace amounts of L-lysine, as indicated by GC of the di- $N$ trifluoroacetyl aminoacyl- $R$-(-)-but-2-yl esters.

Dansylation showed that a free $\delta$-amino group of ornithine was present in the lipid; this was confirmed by the absence of a positive ninhydrin reaction after treatment of the lipid with diazomethane, due to its cyclization into a lactam (Thiele et al., 1984), in agreement with the known spontaneous reaction of ornithine esters (Greenstein \& Winitz, 1961). Thus the amide bond was on the $\alpha$-amino group of ornithine.

Mild alkaline deacylation by transesterification with methanol gave both a mixture of fatty acid methyl esters, in which the major component was identified by GC as tuberculostearic acid (10-methyloctadecanoic acid) and a ninhydrin-positive compound $\left(R_{F} 0.09\right.$ with solvent $\left.\mathrm{A}\right)$ corresponding to the $O$-deacylated ornithine-amide lipid (formula 1). After acidic hydrolysis of the latter, a<smiles>CCCCCCC(O)CC(=O)NC(CN)C(=O)O</smiles>

Formula 1 mixture of 3-hydroxy-acids was obtained, and analysed as methyl esters and $O$-trimethylsilyl derivatives.

\section{Mass spectrometric analysis}

The positive FAB mass spectrum of the intact lipid exhibited several signals $14 \mathrm{Da}$ apart, which can be assigned to protonated molecular ions of difierent homologues (Fig. 2). The two major signals arose at $m / z 695$ and $m / z 723$.

The fragmentation pattern of each ion was determined from the coresponding CID-MIKE spectrum (Fig. 3). From this, $m / z 695$ was found to decompose mainly into $m / z$ 397. This indicates that the loss of 298 Da can be attributed to the loss of a $\mathrm{C} 19: 0$ fatty acid. This fragment is flanked by two others, $18 \mathrm{Da}$ apart, at $m / z 379$ and $m / z 415$ respectively. The former can be attributed to the successive loss of water while the latter corresponds to the loss of a $\mathrm{C} 19: 0$ ketene from the protonated molecular ion. At low mass range, a characteristic signal at $m / z 115$ corresponds either to the acylium ion from ornithine (formula 2) or to its protonated cyclic form (formula 3 )<smiles></smiles>

Formula 2 or<smiles>[NH3+][C@H]1CCCNC1=O</smiles>

$m / z 115$

Formula 3
A similar pattern was observed from $m / z$ 723: loss of $298 \mathrm{Da}$ due to formation of the ornithine fragment.

The behaviour of the minor homologues was slightly different. While $m / z 709$ still lost $298 \mathrm{Da}$ (C19:0 fatty acid), it exhibited a peak at $m / z 129$, corresponding to the acylium ion from lysine. $m / z 691$ gave a more complicated pattern, showing the loss of different fatty acids, while forming the ornithine fragment only.

The C19:0 fatty acid which was lost from the protonated molecular ion was clearly identified as tuberculostearic acid by studying the fragmentation of its carboxylate anion. The negative-ion FAB mass spectrum of the intact lipid exhibited a large peak at $m / z 297$, due to a fragmentation corresponding to the deprotonated molecular ion of the C19:0 fatty acid moiety. This fragmentation is the well-known deacylation reaction from ester-containing lipids in negative ion FAB-MS. A CID-MIKE analysis of this ion produced its chargeremote fragmentation spectrum (Tomer et al., 1983). It clearly showed a methyl branch on the ninth carbon atom from the methyl end, as indicated by the weak ninth signal in the regularly spaced fragment series from 


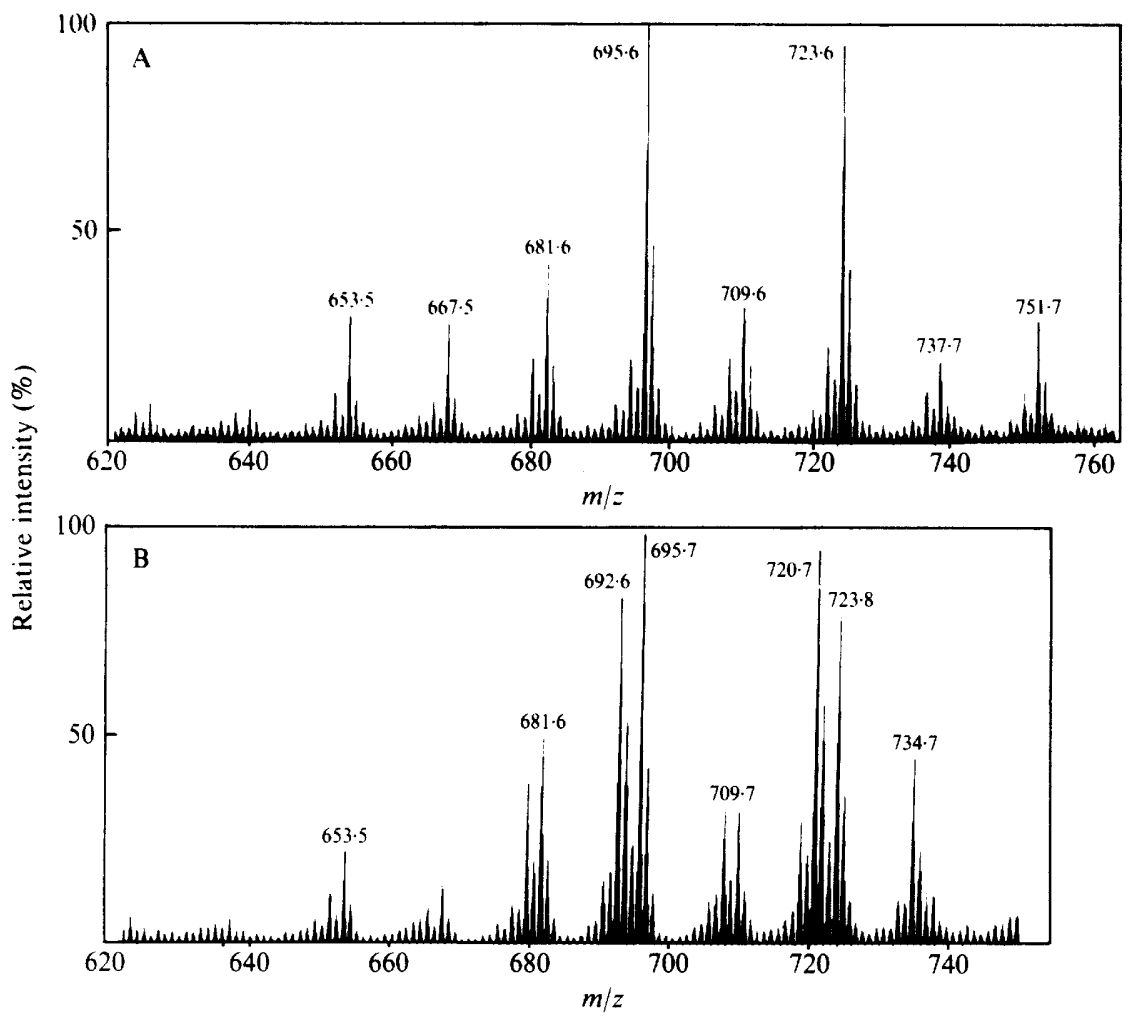

Fig. 2. Positive ion FAB mass spectra. A, amino acid amide-lipids from $M$. tuberculosis strain Canetti. B, amino acid amide-lipids from $M$. bovis BCG. This sample is contaminated by phosphatidylethanolamine (see text). Exact mass values are indicated on this Figure; these values are not integer numbers since the mass of $\mathrm{H}$ is 1.007 not 1.000 . In the corresponding text, mass values are given as the integer just below the exact value (to facilitate calculations).

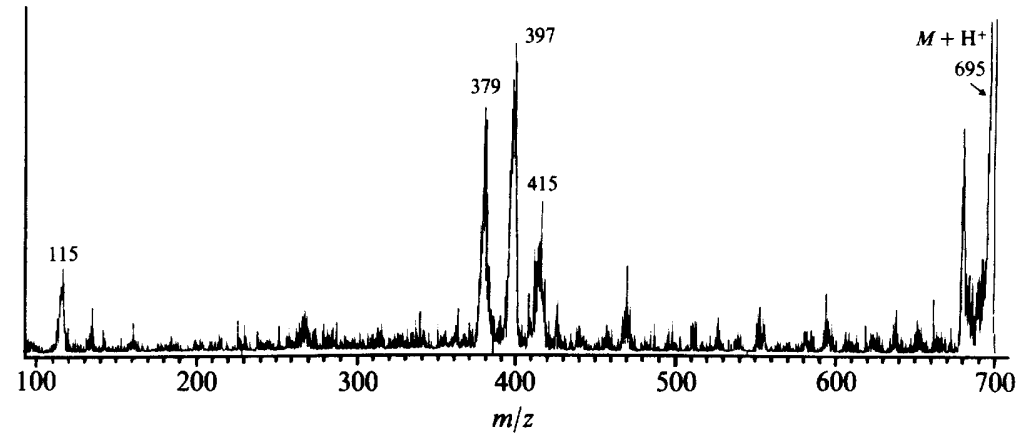

Fig. 3. CID-MIKE spectrum of the main component (protonated molecular ion) from the ornithine-amide lipid of $M$. tuberculosis strain Canetti - see text for interpretation.

the parent ion. Thus the formation of $m / z 297$ in the negative-ion FAB mass spectrum indicated the presence of ester-bound tuberculostearic acid.

The characterization of all the lipid components of this compound was finally achieved by GC/MS analysis (electron-impact ionization) of the fatty acids released by acid hydrolysis. These acids were analysed after methy- lation with diazomethane followed by trimethylsilylation. Such 3-hydroxy-fatty acid derivatives presented a characteristic fragment ion at $m / z 175$ (formula 4). Spectra having this fragment in the GC/MS analysis were selected by the computer program, and the molecular mass of the corresponding hydroxy-fatty acid derivative was determined from the $m / z$ value of the 
intense $M^{+}-15$ ion (i.e. the $M^{+}-\mathrm{CH}_{3}$ ion from trimethylsilyl derivatives, which do not give the molecular ion).

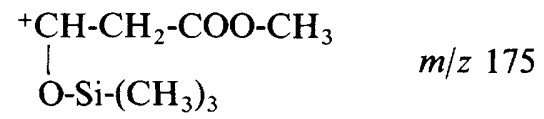

Formula 4

This analysis showed that 3-hydroxyoctadecanoic and 3-hydroxyeicosanoic acids were the main amide-linked components, whereas tuberculostearic acid was the main ester-bound fatty acid, together with small amounts of palmitic and stearic acids. These fatty acids are very characteristic of this type of lipid since the 3-hydroxyfatty acids were not previously detected in other mycobacterial lipids, and although tuberculostearic acid is specific to mycobacteria and related bacteria, it is not the major fatty acid in these micro-organisms.

\section{Ornithine-amide lipids from $M$. bovis (BCG strain)}

This lipid was present in very small amounts in $M$. bovis and could not be isolated in pure form by TLC, the fraction being contaminated by phosphatidylethanolamine. Nevertheless, the positive FAB mass spectrum of this mixture clearly allowed these two lipids to be distinguished: the ornithine lipids gave odd-numbered $m / z$ values for their protonated molecular ion (due to the presence of two nitrogen atoms) (Fig. 2B) whereas phosphatidylethanolamine gave even-numbered $\mathrm{m} / \mathrm{z}$ values (due to a single nitrogen atom). The oddnumbered ions possessed the same mass as the lipid from $M$. tuberculosis strain Canetti, namely $m / z 723$ and $m / z$ 695. Their CID-MIKE spectra resembled those of the Canetti lipids: an abundant ion showing the loss of a C19:0 fatty acid, flanked by two satellites $18 \mathrm{Da}$ apart, and the ornithine fragment at $m / z 115$. GC/MS analysis of the fatty acids (analysed as methyl ester and trimethylsilyl ether derivatives) revealed that 3-hydroxyeicosanoic and 3-hydroxydocosanoic acids were the main hydroxylated fatty acids linked through an amide bond. The C19:0 fatty acid was identified as tuberculostearic acid.

It is thus clear that ornithine-amide lipid, in contrast to the structure previously postulated (Promé et al., 1969), contains no diol-ester group. The presence of an ethanediol residue, as postulated for ornithine-lipid of M. bovis (BCG) (Promé et al., 1969) and Brucella melitensis (Promé et al., 1969; Thiele \& Schwinn, 1973) probably resulted from contamination of samples with other mycobacterial lipids. Indeed, no attempt was made to quantify this diol and to check if the amount present corresponded to the postulated structure. Diol-lipid contaminants were likely to occur since it has long been known that ethanediol is present in minor amounts in mycobacteria, linked in various unidentified lipids presenting a large polarity range (Demarteau-Ginsburg \& Miquel, 1962).

\section{Ornithine-amide lipids of some other strains}

Ornithine-amide lipids were sought in some other strains of the M. tuberculosis-bovis complex and in some other mycobacteria. For a rapid survey, lipids were mildly deacylated in order to eliminate nitrogen-containing compounds in which the amino moiety was linked to the lipid moiety by an ester bond (e.g. phosphatidylethanolamine, aminoacyl diglycerides, aminoacyl phosphatidylglycerol). These deacylated products were analysed by TLC and visualized by reaction with ninhydrin. A more precise identification of the native compounds was then achieved by MS.

Ornithine-amide lipids were detected in all the slowgrowing pathogenic strains tested, except the avirulent M. tuberculosis strain H37 Ra (Table 1). It is worth noting that an ornithine-amide lipid was present in the recent clinical isolate (strain IP 88628) included in our screening. In contrast, these amide-lipids were not detected in the fast-growing strains tested. However, an amino acid ester lipid was present in two out of the six fast-growing strains tested (Table 1): the structure of a lysyldiglyceride from $M$. phlei was recently elucidated (Lerouge $e t$ al., 1988), and the amino acid lipid from $M$. aurum is under investigation.

\section{Conclusions}

Ornithine-amide lipids from the slow-growing mycobacteria studied here have the same general structure as those produced by some Streptomyces strains and by many Gram-negative bacteria. It is thus likely that most, if not all, ornithine-amide lipids described in the literature have this same general structure (Fig. 1). Mycobacterial ornithine-amide lipids are distinct only in their $O$-acylation by, predominantly, tuberculostearic acid.

It is worth noting that ornithine-amide lipids are not restricted to a few bacterial genera, but are present in a large variety of micro-organisms, including the three pathogenic Mycobacterium species examined here. As seen in Table 1 , these lipids were not detected in the avirulent $M$. tuberculosis strain $\mathrm{H} 37 \mathrm{Ra}$. It is known that these lipids exhibit biological effects, e.g. haemolytic 
activity and haemagglutination (Kawai et al., 1985), and macrophage stimulation to generate immunoregulatory substances (Kawai \& Akagawa, 1989). Thus ornithineamide lipids could be one of the pathogenicity factors of virulent bacteria.

\section{References}

Asselineau, J., Pichinoty, F., Promé, D. \& Promé, J. C. (1988). Composition des lipides complexes de Flavobacterium meningosepticum. Annales de l'Institut Pasteur/Microbiologie 139, 159-170.

Batrakov, S. \& Bergelson, L. D. (1978). Lipids of the streptomyces. Structural investigation and biological interrelation. A review. Chemistry and Physics of Lipids 21, 1-20.

Daffé, M., Lanéelle, M. A., Asselineau, C., Levy-Frébault, V. \& DAVID, H. (1983). Intérêt taxonomique des acides gras des mycobactéries: proposition d'une méthode d'analyse. Annales de I'Institut Pasteur/Microbiologie 134B, 241-256.

Daffé, M., Lacave, C., Lanéelle, M. A. \& Lanéelle, G. (1987). Structure of the major triglycosyl phenol-phthiocerol of Mycobacterium tuberculosis (strain Canetti). European Journal of Biochemistry 167, 155-160.

Demarteau-Ginsburg, H. \& Miquel, A. M. (1962). Sur la présence d'éthylène-glycol dans les lipides de mycobactéries. Bulletin de la Société de Chimie Biologique 44, 679-682.

Greenstein, J. P. \& Winitz, M. (1961). Chemistry of the Amino Acids, p. 2483. New York: John Wiley.

KAWAI, Y. \& AKAGAWA, K. (1989). Macrophage activation by an ornithine-containing lipid or a serine-containing lipid. Infection and Immunity 57, 2086-2091.

KaWAI, Y. \& YANO, I. (1983). Ornithine-containing lipid of Bordetella pertussis, a new type of haemagglutinin. European Journal of Biochemistry 136, 531-538.

Kawai, Y., Suzuki, K. \& Hagiwara, T. (1985). Phosphatidylserine and ornithine-containing lipids of Bordetella, haemagglutinins of lipoaminoacid structure, and their control in biomembranes. European Journal of Biochemistry 147, 367-370.
KawaI, Y., Yano, I. \& Kaneda, K. (1988a). Various kinds of lipoaminoacids including a novel serine-containing lipid in an opportunistic pathogen Flavobacterium. Their structure and biological activities on erythrocytes. European Journal of Biochemistry 171, 73-80.

KaWai, Y., Yano, I., Kaneda, K. \& YabuUchi, E. (1988b). Ornithinecontaining lipids of some Pseudomonas species. European Journal of Biochemistry 175, 633-641.

LEDERER, E. (1979). Cord-factor and related synthetic trehalose diesters. In Immunostimulation, pp. 95-110. Edited by L. Chedid, P. A. Miescher \& H. J. Mueller-Eberhard. Berlin: Springer-Verlag.

Lerouge, P., Lebas, M. H., Agapakis-Caussé, C. \& Promé, J. C. (1988). Isolation and structure of a new non-phosphorylated lipoaminoacid from Mycobacterium phlei. Chemistry and Physics of Lipids 49, 161-166.

Mehra, V., Brennan, P. J., Rada, E., Convit, J. \& Bloom, B. R (1984). Lymphocyte suppression in leprosy induced by unique $M$ leprae glycolipid. Nature, London 308, 194-196.

Minnixin, D. E. \& ABDolRahimzadeh, H. (1974). The replacement of phosphatidylethanolamine and acidic phospholipids by an ornithine-amide lipid and a minor phosphorus-free lipid of Pseudomonas fluorescens NCMB 129. FEBS Letters 43, 257-260.

O'LeARY, W. M. \& Wilkinson, S. G. (1988). Gram-positive bacteria. In Microbial Lipids, pp. 117-185. Edited by C. Ratledge \& S. G. Wilkinson. London: Academic Press.

Promé, J. C., LaCaVe, C. \& LaNÉElle, M. A. (1969). Sur les structures de lipides à ornithine de Brucella melitensis et de Mycobacterium bovis (BCG). Compte Rendus de l'Académie des Sciences 269, 1664-1667.

Thiele, O. \& SchwinN, N. G. (1973). The free lipids of Brucella melitensis and Bordetella pertussis. European Journal of Biochemistry 34, 333-334.

Thiele, O., Oulevey, J. \& Hunnemann, D. H. (1984). Ornithinecontaining lipids in Thiobacillus A2 and Achromobacter sp. European Journal of Biochemistry 139, 131-135.

TOMer, K. B., Crow, F. W. \& Gross, M. L. (1983). Location of double bond position in unsaturated fatty acids by negative ion MS/MS. Journal of the American Chemical Society 105, 5487-5488.

WILKINSON, S. G. (1972). Composition and structure of the ornithinecontaining lipid from Pseudomonas rubescens. Biochimica et Biophysica Acta 270, 1-17.

WILKINSON, S. G. (1988). Gram-negative bacteria. In Microbial Lipids, pp. 293-428. Edited by C. Ratledge \& S. G. Wilkinson. London: Academic Press. 